\title{
Comparative analysis of the efficacy of selected gametocide agents in sorghum (Sorghum bicolor [L.] Moench)
}

\author{
Muhammad Ahmad Yahaya ${ }^{1,2^{*}}$, Hussein Shimelis ${ }^{1}$, Mark Laing and ${ }^{1}$, Isack Mathew ${ }^{1}$ \\ ${ }^{1}$ African Centre for Crop Improvement, School of Agricultural, Earth and Environmental Sciences, College of Agriculture, Engineering
and Sciences, University of KwaZulu-Natal, Private Bag X01, Scottsville 3209, Pietermaritzburg, South Africa
${ }^{2}$ Department of Plant Science, Institute for Agricultural Research Samaru, Ahmadu Bello University Zaria, PMB 1044, Kaduna, Nigeria
}

*Corresponding author email: 218086126@stu.ukzn.ac.za

Abstract

A new generation of chemical hybridization agents (CHAs) or gametocides has shown potential to induce male sterility in predominantly self-fertilizing crops, including sorghum (Sorghum bicolor [L.] Moench). There is a lack of information on the relative efficacy of the various available CHAs for largescale application in plant breeding programs. Therefore, the objective of the present study was to compare the relative effectiveness of three selected $\mathrm{CHAs}$ to induce male sterility in sorghum under a controlled environment for hybridization. Foliar applications of three CHAs and a control (ethrel, trifluoromethanesulfonamide [TFMSA], ethyl 4-fluorooxanilate [ $\mathrm{E}_{4} \mathrm{FO}$ ] and distilled water [control]) were tested using three grain sorghum genotypes (ICS-1, ICS-2 and ICS-3) in two seasons. The 24 treatment combinations consisting of 4 levels of CHAs, 3 sorghum varieties and two seasons were laid out using a randomized complete block design with three replications. Data on pollen sterility, pollen diameter, plant height, and panicle height were collected and analyzed. Results showed that the CHAs had significant $(p<0.05)$ differences for efficacy of inducing male sterility in sorghum. Ethrel at a dose of $1 \mathrm{gl}^{-1}$ induced the highest pollen sterility ( $98 \%$ in both seasons) but was highly phytotoxic with at least $60 \%$ mortality in the test population in both seasons, making it unsuitable for practical application. TFMSA ( $2 \mathrm{mg}$ per plant) and $\mathrm{E}_{4} \mathrm{FO}\left(1 \mathrm{gl}^{-1}\right) \mathrm{d}$ induced $93 \%$ male sterility with minimal phytotoxic effects ( 20 to $30 \%$ ). Application of either TFMSA at $2 \mathrm{mg}$ per plant after flag leaf emergence or $1 \mathrm{gl}^{-1}$ of $\mathrm{E}_{4} \mathrm{FO}$ at panicle initiation can be used to successfully induce male sterility in sorghum under greenhouse conditions.

Keywords: Chemical hybridizing agent; emasculation, hybrid seed production; male sterility; sorghum.

Abbreviations: $\mathrm{CHA}=$ chemical hybridization agent, $\mathrm{CMS}=$ cytoplasmic male sterility, $\mathrm{E}_{4} \mathrm{FO}=$ ethyl 4-fluorooxanilate, $\mathrm{HSD}=$ honestly significant difference, $\mathrm{KI}-\mathrm{I}_{2}=$ potassium iodide - iodine, TFMSA = trifluoromethanesulfonamide

\section{Introduction}

Crop genetic improvement has led to enhanced productivity and yield gains globally. Genetic gain in self-pollinated crops, including sorghum, can be enhanced through population improvement and hybrid breeding. Heterosis breeding has the potential to improve sorghum productivity by $40 \%$, which will reduce the yield gap between potential and actual yield (Atokple 2003). However, genetic gain in sorghum has stagnated because of limited genetic variation due to the autogamous nature of the crop, and a lack of effective and reliably cheap systems to produce hybrid seed. Sorghum has perfect flowers that are highly autogamous, with a low level of outcrossing $(<20 \%)$ (Reddy et al., 2008). The flowers are small-sized and numerous, necessitating the use of new technologies for selective sterilization of the pollen grain to facilitate artificial cross-pollination for hybridization. There are several methods, broadly categorized as physical, genetic and chemical, used to circumvent autogamy to allow cross-fertilization in sorghum. Physical or mechanical emascu-lation is the most widely used method, but it is more applicable where a limited amount of hybrid seed is required for breeding or genetic analyses. (Yahaya et al., 2019). Thus, the physical method is not appropriate for producing large amounts of hybrid seed. The most common genetic approach to control autogamy in sorghum is the use of a cytoplasmic male sterility (CMS) technique (Cisar and Cooper, 2003). The CMS system has been used sparingly in Africa because it is difficult to develop, maintain and use the three lines required for hybrid seed production using the CMS technique (Reddy et al., 2008). Also, there is a limit to germplasm accessions that can be used for generating all possible heterotic cross combinations due to strict requirements for maintaining the three-line CMS system. Chemical hybridization agents, also called gametocides, are synthetic chemicals that can induce temporary male sterility for developing breeding populations or producing large quantities of hybrid seed in sorghum (Sleper and Poehlman, 2006). Chemical hybridization agents (CHAs) can readily overcome the limitations posed by the physical and genetic techniques. The use of CHAs is time and labor effective and allows for the generation of more hybrid seed for developing test populations for genetic studies, combining ability analyses and backcross breeding programs. The CHAs induce physiological abnormalities in the male gamete that prevent healthy pollen development and shedding and, ultimately, reduce pollen viability (Sleper and Poehlman, 2006). CHAs prevent the flower from selfpollination, allowing for effective cross-pollination if the female stigma is receptive and compatible with foreign pollen. Various CHAs have been used for hybrid seed production in wheat (Parodi and Gaju 2009), sorghum (Boerman et al., 2019), coriander (Kalidasu et al., 2009), rice (Efisue et al., 2010) and sunflower (Razaq et al., 2016).

In sorghum, Amelework et al., (2016) and Mangena et al., (2018) reported that $\mathrm{E}_{4} \mathrm{FO}$ induced more than $95 \%$ male sterility when applied at a rate of $2 \mathrm{gl}^{-1}$ at the heading stage. Ghebrehiwot et al., (2015) used between 1.0 and $1.5 \mathrm{gl}^{-1}$ of $\mathrm{E}_{4} \mathrm{FO}$ on tef once at the booting stage and reported $96 \%$ to $99 \%$ male sterility, without a significant reduction in female fertility or seed yield. Ethrel has been successful in inducing male sterility in different crop species. Amelework et al., (2016) applied $3.0 \mathrm{gl}^{-1}$ of ethrel on sorghum and recorded $100 \%$ male sterility, while Ghebrehiwot et al., (2015) used $5.0 \mathrm{~g} \mathrm{l}^{-1}$ to achieve a similar success rate in tef. Recently, trifluoromethanesulfonamide (TFMSA) has been successfully used under greenhouse and field conditions to induce temporary male sterility in sorghum without any apparent phytotoxicity in the treated plants (Hodnett and Rooney 2018; Boerman et al., 2019). The CHAs have different modes of action, efficacy and application methods, which should be considered to achieve the highest possible rate of male sterility while preserving the integrity of the female flower. However, CHAs have some 
disadvantages that include high costs and a high risk of phytotoxicity in treated plants when applied at higher dosages. The relative effectiveness of CHAs varies among different test populations and environments. The variation has been attributed to factors such as genotypic differences, differences in application dosages and environmental conditions, and their interactions. There is a need to assess the impact of these factors on the efficacy of the CHAs to determine their practical use in plant breeding and programs for hybrid seed production. Therefore, it is a pre-requisite to evaluate the relative efficacy of CHAs on a given test population and under the prevailing environmental condition before large-scale use in sorghum hybridization. Thus, the objective of the present study was to compare the effectiveness of three selected CHAs in inducing male sterility in sorghum under a controlled environment.

\section{Results}

\section{Analysis of variance on genotype, gametocide and season effects}

The combined analysis of variance revealed that the genotype by gametocide by season interaction effects were significant $(P<0.05)$ for plant height (Table 1). Gametocide effects were significant $(P<0.01)$ for all measured traits except plant height and panicle length. Similarly, there was significant $(P<0.05)$ seasonal variability for all measured traits except pollen sterility and pollen diameter. In contrast, the genotype differences were not significant for all measured traits except plant height.

\section{Mean performance of test genotypes under different gametocides}

Gametocides reduced plant height among the tested genotypes when compared to the control treatment. TFMSA reduced plant height of the genotype ICS-1 to 80.0 and $89.3 \mathrm{~cm}$ in 2018 and 2019 compared to the control, which had plant height of 87.3 and $104.7 \mathrm{~cm}$ in the respective seasons. Similarly, plant height for genotype ICS-2 decreased to 105.0 and $90.3 \mathrm{~cm}$ after $\mathrm{E}_{4} \mathrm{FO}$ treatment in the 2018 and 2019 seasons, respectively. Among the CHAs, ethrel caused 98\% male sterility in genotype ISC-2, which was the highest in both seasons (Table 2 and Figure 1). Ethrel caused the lowest level of female fertility of $34.2 \%$ in genotype ICS-1 in 2018, while genotype ICS-3 had the least female fertility value $(26.7 \%)$ in 2019 . The application of TFMSA and $\mathrm{E}_{4} \mathrm{FO}$ maintained high levels of female fertility (Table 2 and Figure 2). Significant differences were recorded for pollen sterility. Ethrel induced the highest level of pollen sterility at $95.6 \%$ for genotype ICS-2 while the TFMSA caused the least pollen sterility $(78.6 \%)$ in genotype ICS-3 in 2018. Similarly, in 2019, the highest level of pollen sterility (96.4\%) was caused by application of ethrel in genotype ICS-1 (Figure $3)$, while TFMSA caused a lowest level of pollen sterility $(77.6 \%)$ in genotype ICS-2 (Table 2).

\section{Scanning electron microscopy analysis of pollen grains}

The SEM analysis revealed that pollen grain from treated plots were shrunken or disfigured pollen grains with smaller mean diameter in contrast to the healthy pollen from the control plants (Figure 4). Pollen grains in the control plants were ellipsoidal with significantly larger pollen diameter $($ mean $=117.7 \mu \mathrm{m}$ in 2018 and $118.0 \mu \mathrm{m}$ for ICS-1) when compared with treated plants. The smallest pollen diameter of $19.7 \mu \mathrm{m}$ was recorded in ICS-2 after E4FO treatment. In comparison, the same genotype attained the widest diameter of $38.1 \mu \mathrm{m}$ when treated with TFMSA.

\section{Discussion}

Chemical induction of male sterility in sorghum is potentially valuable for hybridization programs to enable genetic analyses, population development and heterosis breeding. Inducing temporary male infertility shortens the amount of time required for successful heterosis breeding and circumvents the need for developing suitable male-sterile and maintaining restorer lines for hybrid breeding, which are critical limiting factors during conventional hybrid breeding of sorghum. Chemical hybridization agents that selectively induce male sterility while maintaining female fertility can bypass these limitations.
The current study evaluated the efficacy of three $\mathrm{CHAs}$ to induce male sterility in sorghum. The differential effects of $\mathrm{CHAs}$ on genotypes due to environmental conditions constitute a considerable challenge because a stable and consistent $\mathrm{CHA}$ would be required for effective induction of male sterility. This suggested that the evaluated CHAs work within a narrow range of conditions, which must be ascertained before embarking on large-scale male sterility induction. The differential response is most likely attributable to variations in temperature and humidity, which are some of the factors that govern biological processes in a plant. Lack of consistency of gametocides across seasons has also been reported on rice genotypes (Efisue et al., 2010). These findings are similar to those of Hodnett and Rooney (2018) and Mangena et al., (2019), who reported that male sterility can be induced in sorghum with appropriate timing for application of CHAs. The significant differences among the gametocides in causing male sterility indicated that the chemical hybridizing agents used in this study had variable efficacies. In the present study, plants treated with gametocides at panicle initiation incurred a significant reduction in plant height compared to control plants. Gametocides such as ethrel can be phytotoxic and cause significant growth impairment and poor vigor in plants leading to stunted growth, which sometimes manifests as reduced plant height. The reduction in plant height can be as a result of death or temporary inhibition of terminal buds, narrowing of leaves, chlorosis and interference with water absorption potential to support optimal plant growth. The potential reduction in plant height was also previously reported by Kalidasu et al., (2009) in coriander and Chakraborty and Devakumar (2006) in wheat, which was attributed to the effects of ethrel and $\mathrm{E}_{4} \mathrm{FO}$. In contrast, Loussaert (2004) reported no significant reduction in plant height when TFMSA was applied on maize. Male sterility and female fertility are essential aspects when measuring the efficacy of any CHA. A desirable CHA is one that can induce high levels of male sterility without a significant reduction in the fertility of the female gamete (Loussaert 2004). The induction of male sterility facilitates the production of large amounts of hybrid seed and has the potential for commercial application in seed production. TFMSA and $E_{4} F O$ induced high levels of male sterility with minimal adverse impact on female fertility, showing that these two $\mathrm{CHAs}$ could be used in large-scale hybrid seed production. Male sterility values $\geq 90 \%$ were recorded in all genotypes, which suggested that the CHAs were highly effective as male gametocides. Their usefulness in hybrid seed production will, therefore, be determined by their impact on the fertility of the female flower. Although ethrel recorded the highest value for male sterility ( $98.5 \%$ in 2018 and $98.4 \%$ in 2019) among the three gametocides, it significantly reduced female fertility $(60.9 \%$ in 2018 and $73.3 \%$ in 2019). Ethrel reduced the viability of both anthers and stigma, making it less useful as a gametocide for hybrid seed production. Amelework et al., (2016) asserted that an effective CHA for hybrid seed production must induce more than $90 \%$ male sterility in sorghum. However, the CHA must have minimal adverse effects on the female flower to facilitate cross-pollination. From the staining test, pollen sterility was confirmed under the microscope based on the extent of staining using potassium iodide iodine $\left(\mathrm{KI}^{-} \mathrm{I}_{2}\right)$, which reacts with starch. During healthy pollen development, the conversion of carbohydrate substrates to starch for energy occurs in preparation to support fruit development (Amelework et al., 2016). When the CHA interferes with pollen development, the starch conversion process does not take place, and the $\mathrm{KI}-\mathrm{I}_{2}$ staining reaction would test negative. The lack of staining and the visible appearance of a transparent pollen grain when viewed under a light microscope are due to the absence of starch, which would indicate that the CHA successfully interfered with pollen development. In contrast, pollen grains from the control plots were deeply stained, showing the presence of starch as a result of uninterrupted pollen development. According to Loussaert (2004), male sterility was induced by TFMSA by interfering with proline and starch transportation, resulting in the disruption of the feedback loop between proline synthesis and accumulation at the respective sites. Loussaert (2004) further suggested that the osmotic potential of the 


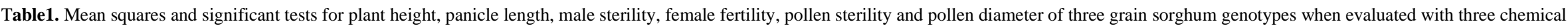
hybridizing agents in two seasons.

\begin{tabular}{|c|c|c|c|c|c|c|c|}
\hline Source of variation & Degree of freedom & Plant height $(\mathrm{cm})$ & Panicle Length $(\mathrm{cm})$ & Male Sterility (\%) & Female fertility (\%) & Pollen sterility (\%) & Pollen diameter $(\mu \mathrm{m})$ \\
\hline Replication & 2 & 55.43 & 9.11 & 89.31 & 332.98 & 74.84 & 488.53 \\
\hline Genotype (V) & 2 & $64963.35 * * *$ & 8.93 & 18.30 & $565.30^{*}$ & 122.40 & 231.68 \\
\hline Gametocide (G) & 3 & 232.33 & 23.71 & $35520.07 * * *$ & $9397.69 * * *$ & $21157.49^{* * *}$ & $29962.97 * * *$ \\
\hline Season (S) & 1 & $589.39 *$ & $85.59^{* *}$ & $343.96^{* * * *}$ & $1101.81^{* * * *}$ & 141.87 & 276.95 \\
\hline VxG & 6 & $479.63^{* * *}$ & 17.33 & 16.43 & 264.01 & 44.97 & 105.21 \\
\hline VxS & 2 & $1098.76 * * *$ & 0.18 & 0.50 & 54.06 & 32.10 & 20.01 \\
\hline VxGxS & 8 & $1006.14 * * *$ & 0.79 & 10.74 & 90.04 & 62.38 & 31.70 \\
\hline Error & 46 & 94.23 & 8.47 & 25.40 & 141.57 & 63.39 & 130.26 \\
\hline
\end{tabular}

Error $*, * * * * * *$ denote significant effect at $\mathrm{P}=0.05, \mathrm{P}=0.01$ and $\mathrm{P}=0.001$, respectively.

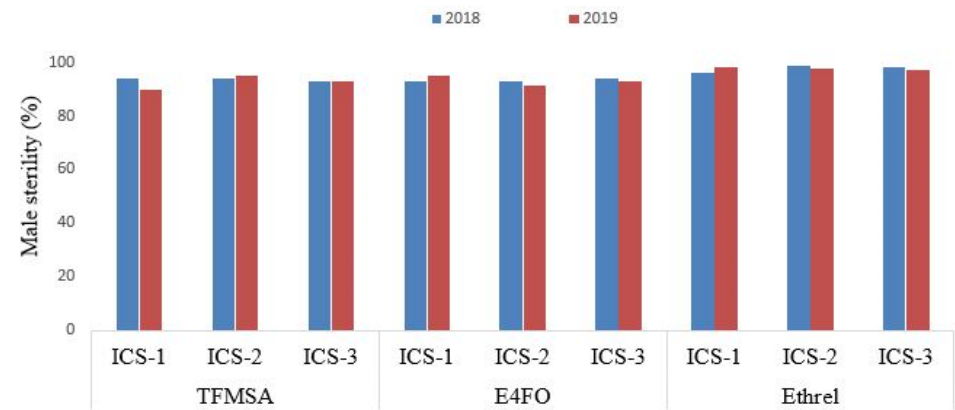

Sorghum genotypes and chemical hybridizing agents

Figure 1: Male sterility (\%) of three sorghum genotypes (ICS-1, ICS-2 and ICS-3) induced by three chemical hybridizing agents (trifluoromethanesulfonamide [TFMSA], ethyl 4

fluorooxanilate $[\mathrm{E} 4 \mathrm{FO})$ and ethrel) in two seasons.

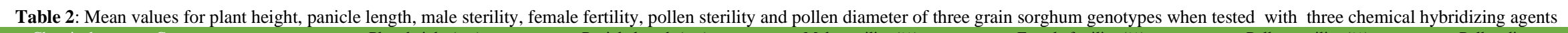

\begin{tabular}{|c|c|c|c|c|c|c|c|c|c|c|c|c|c|}
\hline \multirow{2}{*}{$\begin{array}{c}\text { Chemical } \\
\text { hybridizing agents }\end{array}$} & \multirow[t]{2}{*}{ Genotype } & \multicolumn{2}{|c|}{ Plant height $(\mathrm{cm})$} & \multicolumn{2}{|c|}{ Panicle length $(\mathrm{cm})$} & \multicolumn{2}{|c|}{ Male sterility (\%) } & \multicolumn{2}{|c|}{ Female fertility $(\%)$} & \multicolumn{2}{|c|}{ Pollen sterility (\%) } & \multicolumn{2}{|c|}{ Pollen diameter $(\mu \mathrm{m}$} \\
\hline & & 2018 & 2019 & 2018 & 2019 & 2018 & 2019 & 2018 & 2019 & 2018 & 2019 & 2018 & 2019 \\
\hline \multirow[t]{3}{*}{ TFMSA $\quad(2 \mathrm{mg})$} & ICS-1 & 80.0 & 89.3 & 14.3 & 15.5 & 94.2 & 89.9 & 80.2 & 74.1 & 83.0 & 85.0 & 23.0 & 28.4 \\
\hline & ICS-2 & 110.7 & 111.3 & 13.2 & 13.7 & 93.8 & 94.9 & 75.6 & 78.3 & 80.3 & 77.6 & 22.3 & 38.1 \\
\hline & ICS-3 & 200.0 & 143.0 & 18.0 & 18.0 & 93.1 & 92.8 & 75.1 & 74.0 & 78.6 & 81.6 & 26.4 & 33.9 \\
\hline \multirow{3}{*}{$\begin{array}{l}\mathrm{E}_{4} \mathrm{FO} \\
\left(1 \mathrm{gl}^{-1}\right)\end{array}$} & ICS-1 & 87.3 & 78.0 & 13.7 & 16.3 & 93.1 & 95.3 & 77.2 & 72.6 & 84.7 & 84.3 & 28.0 & 27.9 \\
\hline & ICS-2 & 105.0 & 90.3 & 16.2 & 18.3 & 92.7 & 91.6 & 68.4 & 76.8 & 90.0 & 80.3 & 19.7 & 23.0 \\
\hline & ICS-3 & 187.3 & 191.7 & 12.0 & 15.3 & 94.1 & 93.1 & 77.3 & 71.7 & 82.8 & 83.0 & 23.5 & 27.5 \\
\hline \multirow{3}{*}{$\begin{array}{l}\text { Ethrel } \\
(1 \mathrm{ml} / \mathrm{l})\end{array}$} & ICS-1 & 87.3 & 92.0 & 11.7 & 13.0 & 95.9 & 98.4 & 34.2 & 45.4 & 94.9 & 96.4 & 25.2 & 33.9 \\
\hline & ICS-2 & 107.7 & 103.3 & 13.5 & 14.3 & 98.5 & 97.6 & 39.1 & 28.8 & 95.6 & 93.9 & 28.3 & 27.0 \\
\hline & ICS-3 & 194.0 & 184.0 & 13.0 & 15.7 & 98.1 & 97.4 & 40.1 & 26.7 & 91.5 & 96.4 & 22.7 & 29.8 \\
\hline \multirow[t]{3}{*}{ Control } & ICS-1 & 87.3 & 104.7 & 14.0 & 17.3 & 0.0 & 0.0 & 100.0 & 100.0 & 19.0 & 8.2 & 117.7 & 118.0 \\
\hline & ICS-2 & 120.0 & 130.7 & 14.0 & 18.7 & 0.0 & 0.0 & 100.0 & 100.0 & 3.2 & 14.6 & 105.1 & 99.5 \\
\hline & ICS-3 & 209.0 & 188.7 & 15.0 & 18.5 & 0.0 & 0.0 & 100.0 & 100.0 & 13.8 & 15.8 & 104.9 & 106.9 \\
\hline \multicolumn{2}{|l|}{ Mean } & 131.3 & 125.6 & 14.0 & 16.2 & 71.1 & 70.9 & 72.3 & 70.7 & 68.1 & 68.1 & 45.6 & 49.5 \\
\hline \multicolumn{2}{|l|}{ CV (\%) } & 6.1 & 9.0 & 11.6 & 22.6 & 3.6 & 4.6 & 17.5 & 13.9 & 5.8 & 11.9 & 23.0 & 25.3 \\
\hline \multicolumn{2}{|l|}{ LSD $(5 \%)$} & 6.8 & 9.6 & 1.4 & 3.1 & 2.1 & 2.8 & 10.7 & 8.3 & 3.4 & 6.9 & 8.9 & 10.6 \\
\hline \multicolumn{2}{|l|}{$\mathrm{R}^{2}$} & 1.0 & 1.0 & 0.6 & 0.4 & 1.0 & 1.0 & 0.8 & 0.9 & 1.0 & 1.0 & 1.0 & 0.9 \\
\hline
\end{tabular}




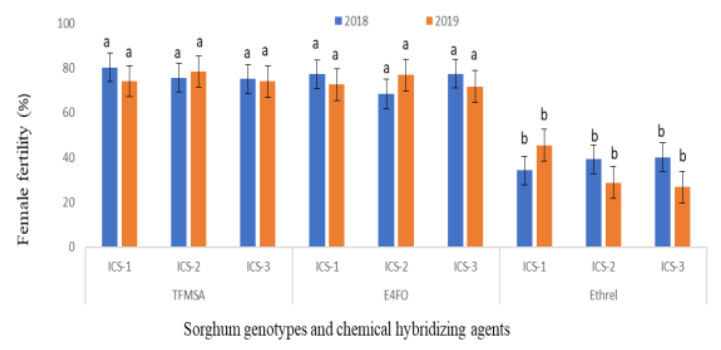

Fig 2: Female fertility (\%) after application of CHAs (trifluoromethanesulfonamide [TFMSA], ethyl 4-fluorooxanilate [E4FO) and ethrel) on three sorghum genotypes (ICS-1, ICS-2 and ICS-3). Columns with the same letter do not significantly differ $(p \leq 0.05)$ according to the Tukey's test
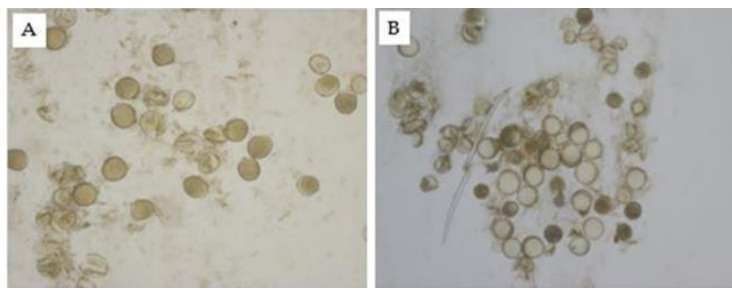

Fig 3: Sterile pollen of ICS-1 genotype following treatment with ethrel vis- $\grave{a}$-vis fertile pollen from the control plot as revealed by the $\mathrm{KI}-\mathrm{I}_{2}$ staining test using a light microscope. Note: $(A)=$ fertile pollen grains and $(B)=$ sterile pollen grains. Bars: $A$ and $B=100 \mu \mathrm{m}$
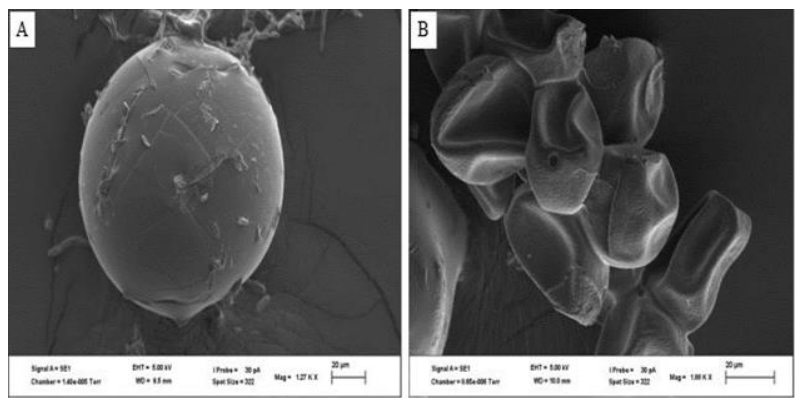

Fig 4: Sterile pollen of ICS-1 genotype following treatment with trifluoromethanesulfonamide (TFMSA) vis- $a$-vis fertile pollen from the control plot as revealed by scanning electron microscope (SEM). Note: $(A)=$ fertile pollen grain and $(B)=$ sterile pollen grains. Bars: $A$ and $B=$ $20 \mu \mathrm{m}$

developing microspores during starch accumulation is modulated by proline, and blockage of its transport may cause microspore abortion. Amelework et al., (2016) and Chakraborty and Devakumar (2006) suggested that male sterility is induced by ethrel and $\mathrm{E}_{4} \mathrm{FO}$ by blockage of the processes leading to starch synthesis or its metabolism. There was a moderately low level of male sterility $(19.0 \%)$ in the control treatment. Natural male sterility can occur due to fluctuations in environmental conditions such as temperature (Prasad et al., 2006). High temperatures experienced in the greenhouse resulted in the abortion of pollens in the controlled plot. Interference by the CHAs during pollen development significantly reduced pollen diameter in comparison to the control treatment. The smaller diameter observed in $\mathrm{CHA}$ treated pollen further showed that $\mathrm{CHAs}$ reduced the size of the pollen grain, which has negative implications on the fertility of the male gametes. The size of the pollen grain is correlated to food and energy reserves required during fertilization (Chakraborty and Devakumar 2006). The sterile pollen grains appeared compressed and irregular in shape due to a delay in the degeneration of the tapetum of the anther. A short delay in tapetum degeneration hampers the possibility of developing healthy pollen grains and partial or complete abortion can occur as a result depending on the extent of the degeneration. Significant changes in pollen morphology due to application of CHAs have been reported by Amelework et al., (2016) on sorghum, Chauhan et al., (2009) on tree cotton (Gossypium arboretum L.) and Chakraborty and Devakumar (2006) on wheat.

\section{Materials and methods}

\section{Experimental site}

Two experiments were performed during 2018 (rainy season) and 2019 (dry season) at the Controlled Environment Facility, University of

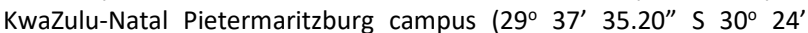
$\left.18.60^{\prime \prime} \mathrm{E}\right)$, South Africa.

\section{Chemical formulation and application}

The TFMSA (Sigma-Aldrich, United Kingdom) was dissolved in an aqueous solution containing glycerol (5\%) and Tween 20 (0.25\%) and applied at a rate of $2 \mathrm{mg}$ per plant. The $\mathrm{E}_{4} \mathrm{FO}$ (Industricord, Beijing, China) was dissolved in dimethyl sulfoxide (DMSO) (1:6 w/v), and $2 \%$ Tween 80 was added to make an $\mathrm{E}_{4} \mathrm{FO}$ concentrate. An $\mathrm{E}_{4} \mathrm{FO}$ solution of $1 \mathrm{gl}^{-1}$ concentration was prepared by diluting with distilled water. An aqueous solution of ethrel (Farmers Agri-Care, Pietermaritzburg, South Africa) was made by dissolving $1 \mathrm{ml}$ of ethrel per liter of distilled water and adding $2 \%$ Tween 80 . The TFMSA was applied with a $3 \mathrm{ml}$ disposable plastic pipette onto the youngest fully expanded leaves of each plant at the flag leaf emergence stage. The TFMSA was spread on the blade with a paintbrush that was previously saturated with the TFMSA solution to ensure an even and thorough distribution of the chemical. The $\mathrm{E}_{4} \mathrm{FO}$ and ethrel were sprayed onto the panicles of the respective test plants at the heading stage using an atomizer, until runoff. Approximately, TFMSA was applied at a rate of $2 \mathrm{mg}$ per plant, while $\mathrm{E}_{4} \mathrm{FO}$ and ethrel were each used at a rate of 8 to $10 \mathrm{ml}$ per plant. All chemical applications were carried out early in the morning to ensure stronger adherence and to avoid chemical drift. Controlled plants were sprayed with distilled water.

\section{Plant materials}

Three grain sorghum genotypes (12ICKNSV297-4, 12KNICSV-260, and ICNSL 2014-027-2, designated as ICS-1, ICS-2, and ICS-3, in that order), were sourced from the International Crops Research Institute for the Semi-Arid Tropics (ICRISAT) Kano Station, Nigeria. The genotypes are medium or tall in plant height, medium-late maturing, and drought tolerant.

\section{Planting and trial establishment}

The first experiment was established in the last week of November in 2018 (rainy season) and the second was conducted in last week of May in 2019 (dry season). Each genotype was planted in a plastic pot (300 $\mathrm{mm}$ diameter and $280 \mathrm{~mm}$ depth) filled with Gromor potting media (http://www.gromor.co.za). Four seeds were sown per pot and thinned to two plants per pot two weeks after sowing. Water was supplied adequately to maintain $75 \%$ field capacity, and the plants were fertilized with Agchem hydroponic water-soluble fertilizer (http://www.agchem.co.za). The plants received optimum fertigation using four three-minute cycles a day. Weeds were manually controlled. Appropriate isolation distance was observed for the control plots to avoid chemical drift and pollen contamination.

\section{Experimental design}

The two experiments were conducted using similar experimental designs and data collection protocols. The study involved 24 treatment combinations as follows: three sorghum genotypes, three $\mathrm{CHAs}$ and a control, and two seasons making $3 \times 4 \times 2$ factorial arrangement. Treatments were laid out in a randomized complete block design with three replications per season. Ten pots consisting of 20 plants were allocated to each treatment. In each treatment, ten plants were randomly selected and tagged, and the panicles bagged to avoid selfpollination while the rest were left uncovered for open pollination after chemical treatment. Data for each replication was collected based on average measurements of four plants. 


\section{Data collection}

Male sterility was estimated as the difference between the total number of seeds in the control and the number of seeds in the treated plants per plot. Ten panicles from each treatment, including control plants, were harvested at maturity. The number of fertile (filled) and sterile (unfilled) grains per spike were counted after manual threshing and percent male sterility was computed using the formulae adapted from Chakraborty and Devakumar (2006):

Percent male sterility $=\left(\frac{S_{c}-S_{f}}{S_{c}}\right) \times 100$

Where, $S_{c}=$ seeds per panicles in control plants

$S_{f}=$ seeds per panicles in bagged and treated plants

Female fertility was recorded as a proportion of fertilized seeds in a plot relative to the total number of seeds in the control and treated plants. The number of seeds per panicle was counted for treated and untreated plants. Female fertility was determined as follows:

Percent female fertility $=\left(\frac{S_{p}-S_{f}}{S_{c}-S_{f}}\right) \times 100$

Where, $S_{c}=$ seeds per panicles in control plants

$S_{f}=$ seeds per panicles in bagged and treated plants

$S_{p}=$ seeds per panicles in pollinated plants

Pollen sterility was determined by observation of the anthers from treated and control plants under a light microscope. Spikelets from three to four florets were randomly sampled per treatment three to five days after treatment and fixing in $70 \%$ ethanol to avoid pollen desiccation. Anthers were extracted from the spikelets, smeared on a glass slide over a drop of acetocarmine $(1 \%)$, and $\mathrm{KI}-1_{2}(2 \%)$ and examined under a light microscope. Four microscopic fields were used to count sterile and fertile pollen grains. Fertile pollen grains were considered to be well-filled pollen grains of normal size and shape that were wholly or partially stained while sterile pollen grains did not stain and were malformed and shriveled. Pollen sterility was quantified as follows (Amelework et al., 2016):

Percent pollen sterility $=\left(\frac{P_{s}}{P_{s}+P_{f}}\right) \times 100$

Where, $P_{S}=$ number of sterile pollens

$P_{f}=$ number of fertile pollens

Pollen diameter was measured under an electron microscope. Fresh pollen grains from treated and control plants were collected on dry Petri dishes and sieved through a $250-\mathrm{mm}$ mesh to remove large floral particles. The fine pollen grains were mounted onto clean stubs using double-sided adhesive. The samples were coated with a $30 \mathrm{~nm}$ layer of gold using an EIKO IB3 Ion Coater (EIKO Engineering CO., Ltd, Osaka, Japan) at an accelerated voltage of $15 \mathrm{kV}$ Electron at the Microscopy and Microanalysis Unit (MMU) at UKZN. The coated pollen grains were viewed and photographed with a ZEISS EVO LS 15 scanning electron microscope (SEM) (Carl Zeiss, München, Germany). Plant height $(\mathrm{cm})$ was measured from the soil surface to the tip of the panicle. The panicle length $(\mathrm{cm})$ was recorded from the base to the tip of a panicle. Fours randomly selected plants were used to measure the plant height and panicle length and the average recorded per plot.

\section{Data analysis}

The data were analyzed for variability using a factorial randomized block design with three replications using the General Linear Model procedure in the Statistical Analysis System (SAS) software package (SAS, 2010). The genotypes, gametocides and seasons were considered as three factors. The mean values of the genotypes in each replication and each treatment were used for the analysis of variance. The Tukey's honestly significant difference test (Tukey's HSD) was used to test differences among sample means for significance at one present and five per cent levels of probability. The differences between season means were separated by a Student's t-test.

\section{Conclusion}

The study sought to assess the efficacy of three $\mathrm{CHAs}$ before embarking on a large-scale CHA-mediated hybridization program. The results showed that the CHAs had variable effects and successfully induced variable levels of male sterility in sorghum. Ethrel is an effective male fertility suppressant but its applicability in a hybrid seed development programs will be limited by its negative impact on the female gamete that reduces chances of cross-pollination. TFMSA and $\mathrm{E}_{4} \mathrm{FO}$ were considered more applicable in a hybrid development program as they suppressed male gamete development while maintaining the integrity of the female gamete to allow controlled pollination. TFMSA should be applied twice at a rate of $2 \mathrm{mg}$ per plant; the first application after the emergence of the flag leaf and a second application one week later for effective induction of male sterility to facilitate outcrossing in sorghum. Alternatively, applying $\mathrm{E}_{4} \mathrm{FO}$ at $1 \mathrm{gl}^{-1}$ at panicle initiation and another application a week later will be equally effective.

\section{Acknowledgments}

The first author acknowledges the following: the International Crops Research Institute for the Semi-Arid Tropics (ICRISAT) for granting Ph.D. Scholarship under Phase II of the 'Harnessing Opportunities for Productivity Enhancement (HOPE II) for Sorghum and Millets in SubSaharan Africa' project funded by the Bill \& Melinda Gates Foundation (BMGF); the Institute for Agricultural Research Samaru, Ahmadu Bello University Zaria Nigeria for study leave and fellowship and; the African Centre for Crop Improvement (ACCI) of the University of KwaZuluNatal (UKZN) South Africa for technical support. Thanks are due to Lorika Beukes and Ntombozuko Matyumza at the Microscopy and Microanalysis Unit (MMU), Agriculture campus, UKZN for technical assistance at the Microscopy Lab.

\section{References}

Amelework A, Laing M, Shimelis H (2016) Evaluation of effective gametocides for selective induction of male sterility in sorghum. Czech J Genet Plant Breed. 52(4): 163-170.

Atokple IDK (2003) Sorghum and millet breeding in west africa in practice. In workshop on the proteins of sorghums and millets: enhancing nutritional and functional properties for Africa. April 2-4, 2003, Pretoria, South Africa. www.afripro.org.uk

Boerman NA, Hlavinka KB, Zhu W, Dabney AR, Hodnett GL, Rooney WL (2019) Efficacy of the chemical trifluoromethane-sulfonamide as a male gametocide in field-grown sorghum [Sorghum bicolor (L.) Moench]. Euphytica. 215(5): 1-10.

Chakraborty K, Devakumar C (2006) Evaluation of chemical compounds for induction of male sterility in wheat (Triticum aestivum L.). Euphytica. 147(3): 329-335.

Chauhan SVS, Meenu C and Chauhan S (2009) Premature dissolution of microsporocyte callose wall causes male sterility in ethephon treated cotton (Gossypium arboreum L.). J Plant Repro Biol. 1(1): 49-52.

Efisue AA, Tongoona P, Derera J (2010) Appraisal of a chemical-hybridizing agent for emasculation in rice. J New Seeds. 11(1): 40-51.

Ghebrehiwot H, Burgdorf R, Hussein S, Laing M (2015) The efficacy of four gametocides for induction of pollen sterility in Eragrostis tef (Zucc.) Trotter. Afr J Biotechnol. 14(9): 774-780.

Hodnett GL, Rooney WL (2018) Male sterility induction of sorghum using chemical hybridizing agent TFMSA, tri-fluoromethanesulfonamide. Can J Plant Sci. 98(5): 1102-1108.

Kalidasu G, Sarada C, Reddy PV, Yellam T (2009) Use of male gametocide: an alternative to cumbersome emasculation in coriander (Coriandrum sativum L.). J HorticFor. 1: 126-132.

Loussaert D (2004) Trihalogenated methylsulfonamides as specific male gametocides. Sex Plant Reprod. 16(6): 299-307.

Mangena P, Shimelis H, Laing M (2019) Preliminary investigation of the effect of ethyl 4 'fluorooxanilate as a male gametocide of sweet stem sorghum. Acta Agr Scand B-S P. 69(3): 268-274.

Parodi PC, Gaju MDLA (2009) Male sterility induced by the chemical hybridizing agent clofencet on wheat, Triticum aestivum and T. turgidum var. durum. Cienc Investig Agrar. 36(2): 267-276.

Prasad PVV, Boote KJ, Allen LH (2006) Adverse high temperature effects on pollen viability, seed-set, seed yield and harvest index of grain-sorghum [Sorghum bicolou (L.) Moench] are more severe at elevated carbon dioxide levels due to higher tissue temperatures. Agric For Meteorol. 139: 237-251.

Razzaq MK, Rauf S, Akhtar N (2016) Effect of various chemical hybridizing agents on sunflower (Helianthus annuus) seed production. J Seed Technol. 37(1): 23-31.

Reddy BVS, Ashok Kumar A, Sanjana Reddy P, Ramaiah B (2008) Development of malesterile lines in sorghum. In: Sorghum Improvement in the New Millennium. International Crops Research Institute for the Semi-Arid Tropics, Patancheru, Andhra Pradesh, India, Pp.72-78. http://oar.icrisat.org/id/eprint/4338

SAS Institute Inc. (2010) SAS Software release 9.3. Cary, NC, USA: SAS Institute Inc.

Sleper DA, Poehlman JM (2006) Breeding Field Crops. $5^{\text {th }}$ ed. Oxford: Blackwell Publishing. Pp. 127-128.

Yahaya MA, Shimelis H, Laing M, Mohammed MS, Mathew I (2019) Methodologies for hybridization in predominantly self-pollinating crops: a review. J Crop Improv. 34 (2): Pp. 268-289. 